\title{
Virtual Integration Platforms (VIP) - A Concept for Integrated and Interdisciplinary Air Transportation Research and Assessment
}

\author{
Volker Gollnick ${ }^{1}$, Eike Stumpf ${ }^{2}$ and Stephan Lehner ${ }^{4}$ \\ German Aerospace Center (DLR), 21079 Hamburg, Germany \\ Joachim Szodruch ${ }^{3}$ \\ German Aerospace Center (DLR), 21079 Hamburg, Germany
}

\begin{abstract}
This paper introduces the concept of Virtual Integration Platforms (VIP) as a method for the development, integration and assessment of new Air Transportation System (ATS) concepts. The VIP concept aims to enable a meaningful integration and assessment of new technologies on a system-of-systems scale. The approach taken follows a systems engineering-based approach to develop new ATS concepts. We describe three VIPs, each of them focussing on a different market segment: One VIP considers short-to-medium haul air transport, one VIP focusses on long haul transport and one VIP studies new business travel concepts. The scope of a virtual integration platform is based on operational targets for various time horizons. Four main substructures of the air transportation system were identified: aircraft, airport, ATM and airline. This paper also includes two examples to demonstrate the VIP concept and its application.
\end{abstract}

\section{Nomenclature}

ACARE $=$ Advisory Council of Aerospace Research in Europe

ANSP $=$ Air Navigation Service Provider

APRON = Part of the aerodrome set aside for loading, unloading or maintaining aircraft

ATIP = Air Traffic Infrastructure and Processes

ATM $=$ Air Traffic Management

$\mathrm{CDA}=$ Continuous Descend Approach

Clean Sky $=$ European Programme on environmental friendly aircraft and engine technologies

CPACS $=$ Common Parametric Aircraft Configuration Standard

DLR = Deutsches Zentrum für Luft- und Raumfahrt, i.e. German Aerospace Center

EIS $=$ Entry into Service

ETOPS = Extended Twin Engines Operations

JTI $=$ Joint Technology Initiative

KPA $=$ Key Performance Area

KPI $=$ Key Performance Indicator

MRO = Maintenance Repair Overhaul

MTOM = Maximum Take Off Mass

NextGen $=$ American Next Generation ATM System

$\mathrm{N}+3=$ NASA American Next Generation Aircraft Concepts

QSTOL = Quiet Short Take Off and Landing

SES $\quad=$ Single European Sky

SESAR = Single European Sky ATM Research

TIATS $=$ Total Integrated Air Transportation System

${ }^{1}$ Director of Institute of Air Transportation Systems, Blohmstr.18, 21079 Hamburg, AIAA Member

${ }^{2}$ Head of Department, System Analysis Air Transportation, Blohmstr.18, 21079 Hamburg, AIAA Member

${ }^{3}$ Consultant, Institute of Air Transportation Systems, Blohmstr.18, 21079 Hamburg, AIAA Associate Fellow

${ }^{4}$ Research Scientist, Institute of Air Transportation Systems, Blohmstr.18, 21079 Hamburg, AIAA Member 
TRL $=$ Technology Readiness Level

TUHH = Technical University Hamburg-Harburg

VIP $\quad=$ Virtual Integration Platform

\section{Introduction}

$\mathrm{T}$ The air transportation system (ATS) and its substructures have reached a very high level of maturity. However, economical competition, continuously increasing traffic demand as well as environmental relevance require further progress towards a more efficient and environmental compatible air transportation system. There are two principle ways to cope with these challenges. First, one could increase efforts to improve existing technologies and concepts. Second, one could address radically new concepts. A number of research efforts have translated both approaches into challenging future targets. These efforts include the European Vision2020 and the American NextGen programme [1-5]. In the following table the various requirements concerning the envisioned ATS capabilities and characteristics have been summerized.

\begin{tabular}{|c|c|c|c|c|}
\hline Objective & EU (ACARE, ref. 2000) & EU (Flightpath 2050, ref. 2000) & $\begin{array}{l}\text { US }(\mathrm{N}+3, \text { user } \\
\text { def. reference) }\end{array}$ & US (NextGen) \\
\hline $\mathrm{CO}_{2}$ Emissions & $-50 \%$ & $-75 \%$ & $\begin{array}{l}\text { Better than }-70 \% \\
\text { fuel burn }\end{array}$ & $\begin{array}{l}-14 \text { million tons } \\
\text { cumulative }\end{array}$ \\
\hline $\mathrm{NO}_{\mathrm{x}}$ Emissions & $-80 \%$ & $-90 \%$ & Better than $-75 \%$ & \multirow{2}{*}{$\begin{array}{l}\text { Improved } \\
\text { Environmental } \\
\text { Performance }\end{array}$} \\
\hline Noise & $-50 \%$ & $-65 \%$ & $\begin{array}{ll}-71 d B & \text { (below } \\
\text { Stage 4) } & \end{array}$ & \\
\hline Punctuality & 99\% within 15 min. & $\begin{array}{l}\text { within } 1 \text { min regardless of weather } \\
\text { conditions }\end{array}$ & N/A & $\begin{array}{l}20 \% \text { to } 35 \% \text { delay } \\
\text { reduction }\end{array}$ \\
\hline Security & Zero Hijack & $\begin{array}{l}\text { Seamless security for global travel; } \\
\text { resilient air vehicles; secure data } \\
\text { network }\end{array}$ & N/A & $\begin{array}{lll}\text { Provide } & \text { Air } & \text { Transp. } \\
\text { Security } & & \end{array}$ \\
\hline Safety & $\begin{array}{l}\text { Five-fold reduction in avg. } \\
\text { accident rate }\end{array}$ & $\begin{array}{l}<1 \quad \text { accident per } 10 \text { million } \\
\text { commercial flights }\end{array}$ & N/A & $\begin{array}{l}\text { Improved } \quad \text { Safety } \\
\text { Operations }\end{array}$ \\
\hline $\begin{array}{l}\text { Quality and } \\
\text { Affordability }\end{array}$ & $\begin{array}{l}<15 \text { min. in airport for short-haul } \\
<30 \text { min. for long haul }\end{array}$ & $\begin{array}{l}90 \% \text { of travellers within Europe } \\
\text { able to complete door-to-door } \\
\text { journey within } 4 \text { hrs }\end{array}$ & N/A & $\begin{array}{ll}\text { Integrated } & \text { NextGen } \\
\text { Information } & \end{array}$ \\
\hline Throughput & 16 million flights/year & 25 million flights/ year & N/A & $\begin{array}{l}\text { Collaborative Capacity } \\
\text { Management } \\
\text { Collaborative Flow } \\
\text { Contingency } \\
\text { Management } \\
\text { Flexible Separation } \\
\text { Management } \\
\text { Efficient Trajectory } \\
\text { Management }\end{array}$ \\
\hline Others & Cut time to market in half & $\begin{array}{l}\text { Emission-free taxiing } \\
\text { All air vehicles recycable }\end{array}$ & $\begin{array}{l}\text { Exploit metro-plex } \\
\text { concepts }\end{array}$ & $\begin{array}{l}\text { Flexible Airport Facility } \\
\text { and Ramp Operations }\end{array}$ \\
\hline
\end{tabular}

Table I-1: Summary of top level future ATS targets, ref. [1], [5]

Achieving these goals will require, both, new breakthrough technologies as well as sophisticated strategies for integrating these technologies in the air transportation system. To tap the full potential in developing robust technologies for a system with optimum net present value, the entire technology respective task. and system lifecycle needs to be investigated based on technical, ecological and monetary criteria . This requires a comprehensive overall system conceptual design and integration capability for technologies in early research phases. The ability to 
assess technology potentials in early design stages is of paramount importance to engineer and analyse complex systems.

These envisaged changes require research efforts that reach from disciplinary research to a more system-oriented view. Due to the interdisciplinary and integrated character of air transportation, a system-oriented analysis is a logical step to establish a big picture view.

The overall goal is to achieve balanced optima for all relevant substructures and subsystems of the air transportation system. This approach implies that subsystems that are optimal in their own right do not necessarly create an optimal overall system.

The Institute for Air Transportation Systems of the German Aerospace Center (DLR) at the Technical University of Hamburg-Harburg has developed the concept of Virtual Integration Platforms (VIP) to cope with this research task. VIPs are concepts for an entire air transportation system and serve as an environment for task-oriented interdisciplinary and integrated research. VIPs investigate the benefit of various new technologies and study how integrating these technologies changes the interconnections between the substructures of the air transportation system. Especially the idea of a balanced optimization of aircraft, airports, airlines and air traffic infrastructures is new and offers the potential to improve the efficiency of air transportation operations. A consistent definition and adaption of the interfaces between the substructures and/or the subsystems is of major importance for system-level studies.

Furthermore, the results of such interdisciplinary investigations might be used for sensitivity studies supporting the integration process of disciplinary technologies into a complex system. The definition and development of comprehensive air transportation concepts itself is a major research objectives that can provide perspectives for the future beyond 2030+, which addresses the time horizon 2030-2040.

\section{A Systems Engineering Approach for new Air Transportation Concepts Analysis}

The air transportation system comprises a lot of stakeholders and entities. Different approaches have been used to describe the air transportation system, which are mainly driven by either economical or organizational forces, ref. [8].

To define and develop future ATS concepts in a structured way, we have developed a system view the focusses on the stakeholder and the processes, see figure II-1. There, the ATS is decomposed into a) infrastructures, b) users of the infrastructures and c) political/social stakeholders, ref. [9]. At the next level, aircraft, airport, airspace and ATM/CNS represent the ATS infrastructures. These elements enable safe transportation and cargo/passenger handling. Furthermore, these infrastructures are used and/or produced as services or products by airlines, aircraft manufacturers, air navigation service providers (ANSP) or maintenenance repair overhaul services (MRO). Airport operators and financial service providers are users of some of the entities of the infrastructures (e.g. financial service providers might lease aircraft). The passenger is the most important stakeholder because his needs define the requirements on passenger air travel. People or companies who ship goods are the most important stakeholder for freight air travel. Policy makers, lobby groups, research agencies and other public institutes are principle stakholders because of their far reaching influence on the users and the infrastructures of the ATS.

The main infrastructure and user elements of the air transportation system are selected to be put together into a Virtual Integration Platform (VIP). The detailed composition of a VIP depends on the defined research task. To select the adequate model level of detail for the relevant substructures, subystems and components, the setup and especially the definition of the system boundaries must be modular and structured in a logical way. For example, one future long haul transportation concept could include a blended wing body aircraft. This choice would imply that the overall concept also includes a detailed airfield, runway and gate description of adequate airport. A more aggregated airport description is sufficient for investigating a single pilot operation concept 


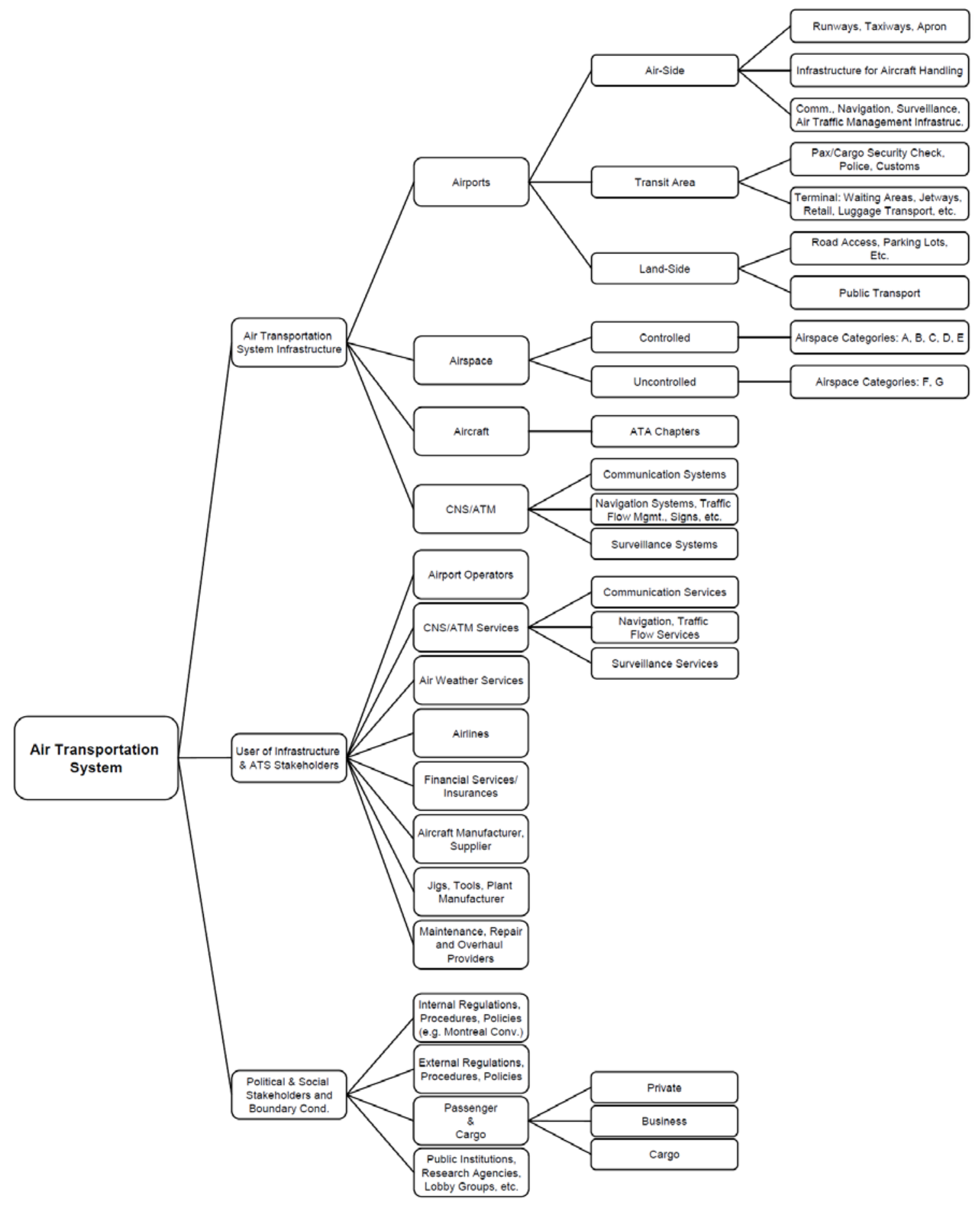

Figure II-1: Structural definition of the air transportation system, ref. [9]

A systems engineering methodology is used to achieve a structured ATS definition, modeling and technology evaluation, ref.[7]. The fundamental research question might be formulated as "Given a certain scenario, what are 
the benefits and drawbacks of implementing a technology in an existing system?”. But also the other way round, the so called "Market Pull" scenarios drive technology research especially on system level, when given technologies are integrated to concepts.

Referring to a principle research task like to achieve $50 \%$ overall $\mathrm{CO}_{2}$ reduction or to realize 4 hours door to door travel within Europe, first future scenarios for the relevant time horizon need to be developed to derive functional and technical requirements for one or more of the air transportation system substructures. At this point a significant difficulty needs to be discussed for complex systems which are referred to as system of systems. Due to the interferring dependencies among the substructures, it is not always possible to break down such global capabilities to substructures requirements in appropriate detail. In addition the overall potential depends heavily on the overall system architecture and the related interfaces. In terms of technology selection and system optimization, the design of an ATS substructure or its subsystems will be directly affected by the design and architecture of the parallel substructure.

Consequently the definition of the overall ATS design is by its nature a complex and global task, and requires a careful, knowledge-basedbalance of selections. To define such a comprehensive ATS concept in a balanced way, the fundamental characteristics and impacts of technologies need to be taken into account. Further the design space of potential solutions is defined by the interfaces between the substructures, subsystems or components.

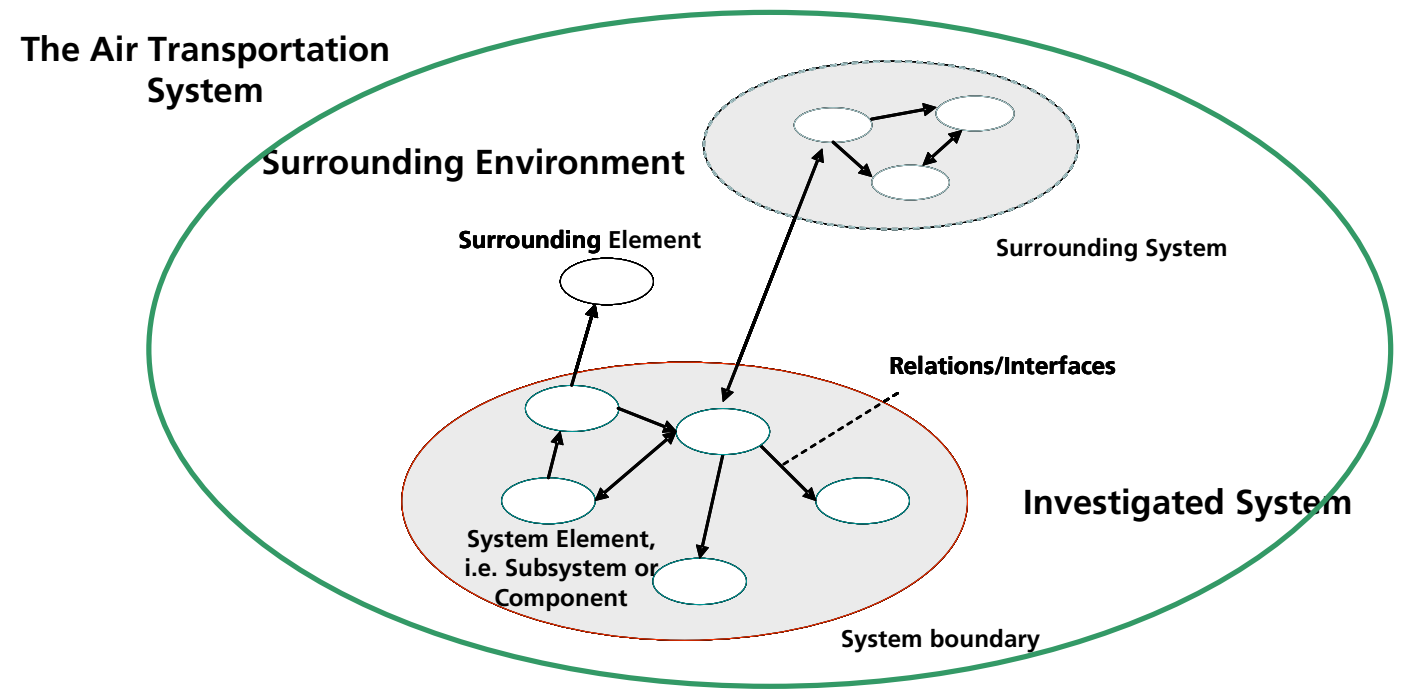

Figure II-2: System of Systems definition and interfaces

Referring to figure II-2 the upper system level defines the design space because the interfaces to the next upper level are restricting potential solutions. Following this logic on the lower levels of systems the design space for new physical solutions is wider, while on the higher level interface compliant definitions create innovation and efficiency.

Technologies in this context are understood as techniques, processes, or procedures including regulations, which impact the capabilities and functioning of the ATS. The benefit or value of a new technology can be described by economical, ecological and performance impacts.

New technologies are developed for the relevant substructure or subsystem level as solutions that comply with the requirements that higher-level systems pose. For the development of those solutions specific new technologies will be defined to compose new concepts, which might fulfil the requirements.

\section{The Virtual Integration Platform Concept}

A Virtual Integration Platform (VIP) is a description of an air transportation system consisting of aircraft, airport, airline and air traffic infrastructure concepts, which are composed of potential new or/and existing technology solutions ensuring interface compliances. 
Following a systems engineering taxonomy, the air transportation system can be hierarchically structured into the system, substructures, subsystems and components as follows:

- The overall air transportation system as the system

- The aircraft, the airline, the air traffic infrastructure, the airport as the substructures in terms of infrastructure and users of the ATS, according to figure II-1.

- e.g. the wing, the avionics, etc. of the aircraft, or e.g. surveillance radar and, air space structures of the air traffic infrastructure, or the terminal, the APRON of the airport as subsystems of one substructure

- e.g. flaps and slats as components of the flight control subsystem of the aircraft, antennas and receivers as parts of the radar subsystem of ATM, check-in areas, gates as components of the airport terminal subsystem, etc....

This hierarchical organization of the VIPs is used to allow a balanced optimisation of the main substructures and achieve multidisciplinary and global goals like those of table I-1.

Each VIP is also a research platform for new technologies and refers to a particular basic transportation mission. Three basic missions have been chosen to represent the main market segments of the air transportation system.

- short range transport,

- long haul transport and

- individual transport.

These distinctions are made because each mission type requires distinctive technologies. For example, high lift capabilities of an aircraft for take-off and landing purposes are important for short range missions. Similarly, compared to a long range mission, the environmental and air traffic infrastructure implications in the vicinity of the airport are mostly influenced by short-range mission considerations. This does not mean, that these aspects are not relevant for a long range mission. However, for a long range mission, more emphasis must be placed on concepts like cabin comfort or emission impacts at high altitudes. It should be noted that short-to-medium and long haul transports are often combined (e.g. in a hub-and-spoke network).

Furthermore, VIPs as future air transportation concepts have to address dedicated time horizons for which technologies might be available for entry into service. To assess the value and benefit of a new technology, it is mandatory to compare it with a reference. For the VIPs, we use the technology status of 2010 as a reference. Based on technology readiness levels, technologies and the target time horizons are classified as follows.

- Technology TRL1 in $2010 \quad$ Time horizon for entry in to service 2050

- Technology TRL3 in $2010 \quad$ Time horizon for entry in to service 2030+

- Technology TRL6 in $2010 \quad$ Time horizon for entry in to service 2020

Given that market constraints pave the way for EIS of a technology, each VIP will focus on one basic transportation mission. In the first step, VIPs are defined for the time horizon 2030+ and later. This decision was made because it can be expected that in 2020 only product upgrades like the A320NEO or upgrades for A380, A350 and B787are realistic. Fig. III-1 shows how the VIP concept is embedded in our technology research and assessment chain[7]. 


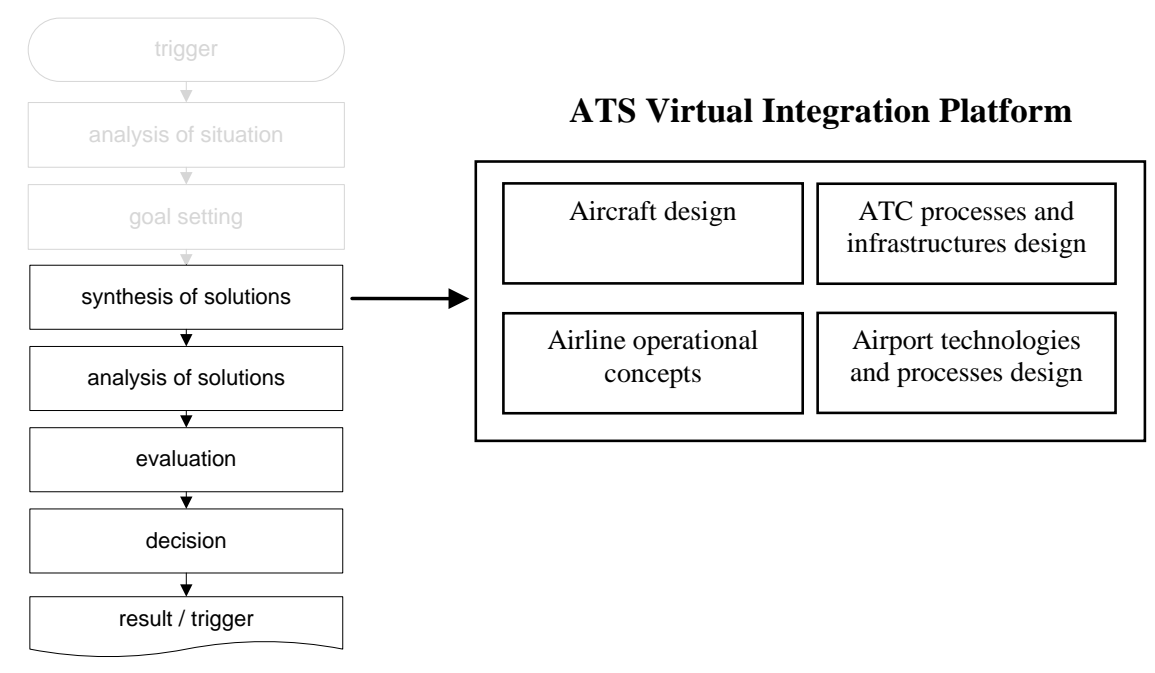

Figure III-1: Integration of VIP into the technology development and assessment process, ref. [7]

There are many technologies being developed in the areas of the different substructures and each technology has its individual benefits. When those technologies are integrated into a higher level system like an airline fleet or the air transportation system, consequences that arise from interactions with other systems may reduce those benefits. The whole is usually more or less than the sum of its parts.

Therefore, a model that integrates new substructure technologies in a higher level system allows considerations that can provide additional knowledge compared to studying the technology on the substructure level alone. The added value results from studies of the behaviour of a technology in a more realistic operational environment. The concept of technology integration is well known on the ATS substructure levels, i.e. aircraft, airport or ATM level. Integration issues on these substructure system levels are the focus of big research efforts like the European JTI and SESAR or the American N+3 and NextGen programmes, which still separate operational issues from platform issues, ref [4], [5]. Analysing the overall operational level by (i) studying technology integration effects, (ii) considering all relevant stakeholders as part of the system and (iii) extending the considered geographical region to an European, an American or a global level will allow the VIP research efforts to make a significant contribution to air transportation research on a system-of-systems scale. This is considered as one of the major advantages of a VIP that it allows studies in a more comprehensice and realistic operational environment.

An example would be a combined assessment of the effects of new high lift systems on an aircraft and continuous descend approaches (CDA) as a flight guidance procedure. On the one hand, the local noise level will be reduced by the flight path of the CDA. On the other hand, CDA requires improved high lift devices which will also have consequences on a more global level (e.g. increased drag and increased fuel burn during cruise) but shall also be designed to reduce noise generation.

There are two major prerequisites for successful system integration research. First, there must be a meaningful technical specification and definition of the entities that might be integrated into the overall system., Second, these entities must be brought together in a logical way.

By broadening the system boundaries, interfaces to other transportation modes, like rail or automotive travel could be included in the analysis of the air transportation system. It would be interesting to study the overall benefits and drawbacks of a tighter-coupling between air transport and other modes of transportation. Remarkably, the new European visionary paper "Flightpath 2050"[6] has put, among others, the intermodal aspect of air transportation into the focus of future research.

While basic research explores solutions to more open questions, system integration research investigates the value of compositions of principle solutions. Therefore, the next sections will present examples that characterize those substructures of the VIP, for which technological solutions are considered. 


\section{Composition and Integration of New Air Transportation Concepts -}

\section{A. Composition and Integration of new air transportation concepts}

To assess the global impacts of potential technologies an overall system concept is required. This section discusses methods to select alternative concepts for a new air transportation concept. In general, there are two approaches to compose new air transportation concepts and integrating new technologies. Depending on the nature of the research problem, one chooses one of them, or a mixture of both.

The first approach uses the reference definitions for aircraft, airport, ATIP and airline of the 2010 status as a baseline. Then single technologies are integrated into the relevant substructures to investigate their benefits on a system level. This approach allows an assessment of the impact of a single technology. This bottom up approach, assembles given substructures and allows an integration on a higher system level. Integrating new technologies in this way, allows a comparison of new systems to existing reference systems. The latter follow the same design goals but represent different technical solutions.

The second way of VIP composition uses the definition of overall new air transportation concepts for future time horizons by a typical top down approach. The goal is to investigate the common benefits of different technologies of all substructures to achieve published targets like the ACARE goals. Therefore, a balanced definition, development and optimisation of new technologies on the overall ATS level is performed. Following this approach, the definition of those new overall concepts considers technologies in a early maturity stage but also highlights functional and technical gaps to be filled by future research.

The selection of technologies to compose new systems is affected by knowledge, experience and gut feeling. Here a process oriented approach following functional chains is the fundamental strategy to select and combine the right technologies.

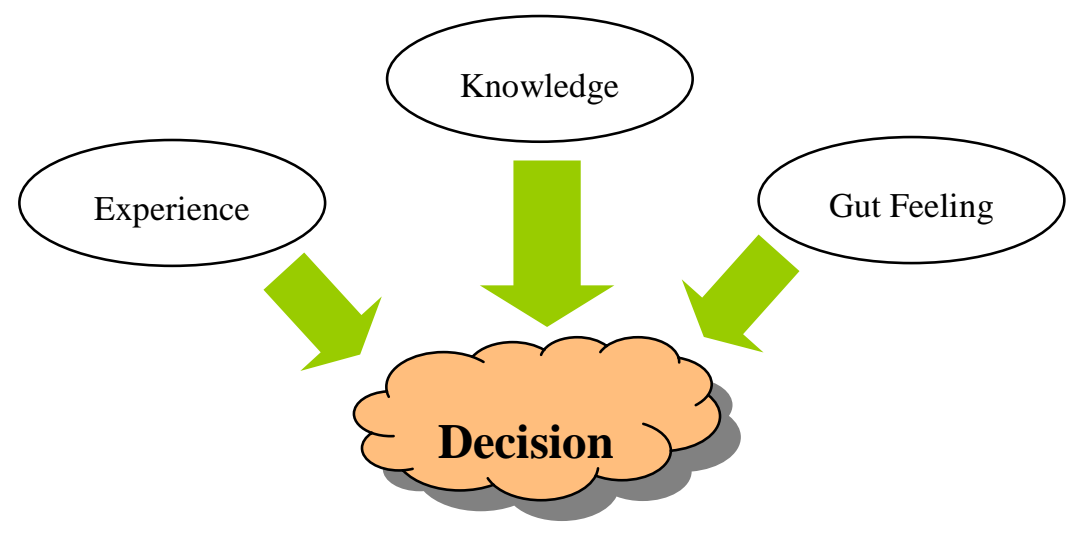

Figure IV-1: Influences on Decisions

Engineers typically tend and expect to make decisions on a pure rational basis. Decision criteria and metrices are used like the "Multi Criteria Decision Making" method to justify the selection and decision process, ref. [19,19,21]. Those methods are fairly complex and require time consuming efforts to select the right method, the right criteria and the right weighting. Especially the later step is mainly driven by gut feeling. Psychologists have shown, that in the background of our thinking processes are running in our brain, which significantly affect our decisions, ref. [14,]. This foreground contradiction is a new field of research to understand how engineers make decisions in a design process and how to manage they use their broad knowledge especially for the decision process, when they define such complex systems like the ATS. Following Michael Griffin of NASA the rational driven decision making processes are called engineering sciences, decision processes based on experience and gut feeling can be named engineering design, ref. [13].

Gigerenzer has shown, that incidentally taken samples driven by gut feelings/intuition will lead to better performance than structured decisions made by experts based on broad and deep information bases analysis, ref. [14]. Especially if we try to look into a future with a lot of uncertainties of a complex system, less information used for the decision making is more efficient than complex strategies, which analyse carefully the past experience. 


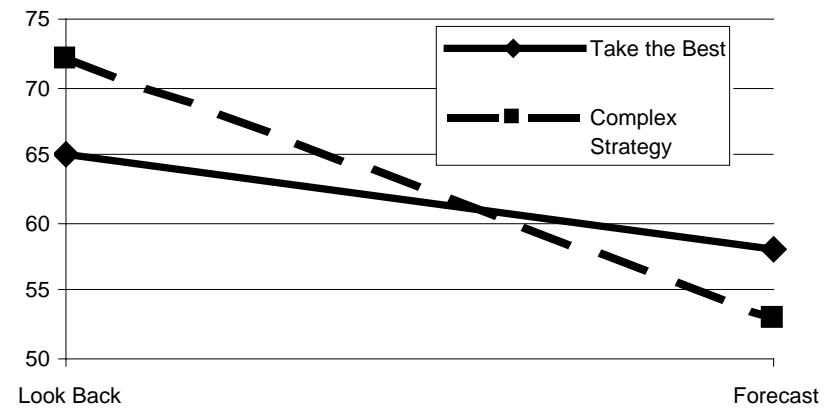

Figure IV-2: Intuition versus complex decision making strategies for forcast and look back analysis, [14]

The reason for this performance of intuition is, that intuition reduces decision making to a very few but paramount criteria. The selection of the right criteria is based on as simple as possible rules, which can be assigned to plausibility.

Following this experience VIPs are defined and composed by applying engineering sciences but also engineering design, because technical decisions are made not only by rational arguments and criteria but they also mainly driven by empirical knowledge and emotions.

Further La Rocca has developed a method of "Knowledge Based Engineering Techniques" as a knowledge based tool set approach that allows to capture product and process multidisciplinary knowledge by means of integrated software applications that can automate repetitive design activities, ref. [14].

Both the knowledge of engineering approaches and interdisciplinary knowledge based software systems will be used to define and develop the VIP. Putting the focus on the future challenges of ATS as mentioned in table I-1and considering future trend scenarios the following VIPs have been defined for 2030+:

\section{- Short haul transport "Silent and Clean"}

- Long haul transport “Comfortable and Clean”

- Individual transport "Fast and Flexible"

\section{B. Exemplary description of the VIP "Silent and Clean"}

As an example for a defined VIP at DLR the concept Short Haul 2030+ "Silent and Clean" is introduced in more detail. Future scenarios for short haul air transportation will mainly depend on the regions to be considered. In regions with a fast growing economy (like Asia), the infrastructure for air transportation can be developed. In contrast, in Europe and the United States only a few new airports will be built. Furthermore, the airspace structure and capacity are limited in these regions. Additionally, short range air transportation is facing a strong competition with high speed trains in Europe. And due to the high urbanisation rate, the cruise ranges are much shorter in Europe. Therefore, two different short range concepts should be developed: one for the European transportation market and one for the growing regions in Asia. In a first step the concept for the European market is developed:

"Silent and Clean" has been chosen as the goal for the global short haul air transport, because short range transport is spatially extended and operational constricitve at the same time. Therefore the ACARE goals on noise and local air quality address the needs of many people. Consequently, for this VIP all technologies are to be considered which especially contribute to these ACARE goals. "Silent and Clean" as a global target imples also the amount of air traffic. Therefore, further ACARE goals like increased capacity on airports as well as efficiency and punctuality will also be addressed. Following this logic one short haul transport concept is composed of:

A short take off and landing aircraft of approximately 150 seats is defined, which provides capabilities for steep departures and approaches, while low emissions and a low noise impact shall be achieved. 


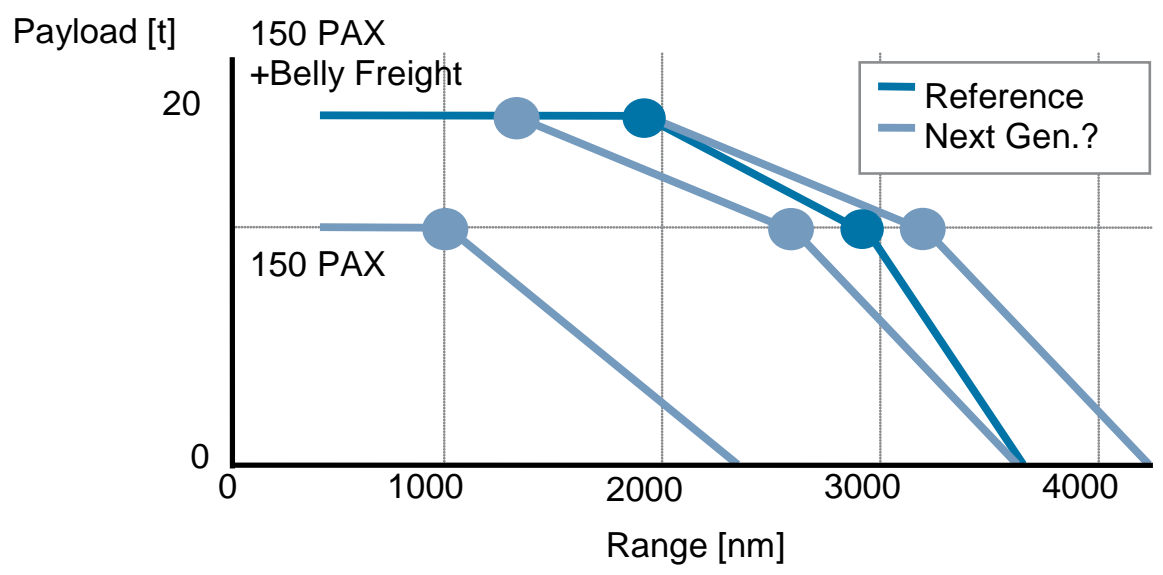

Figure IV-3: Payload Range attributes for new short haul aircraft

Since more than 95\% of the performed flights are below 2000nm the flight performance of such a new short range aircraft will target at this range for which cruise speeds below Mach 0.8 could be beneficial, see figure IV-4. Here the required take off field length is derived from the 95\% coverage of the related airport size, see figure IV-5.

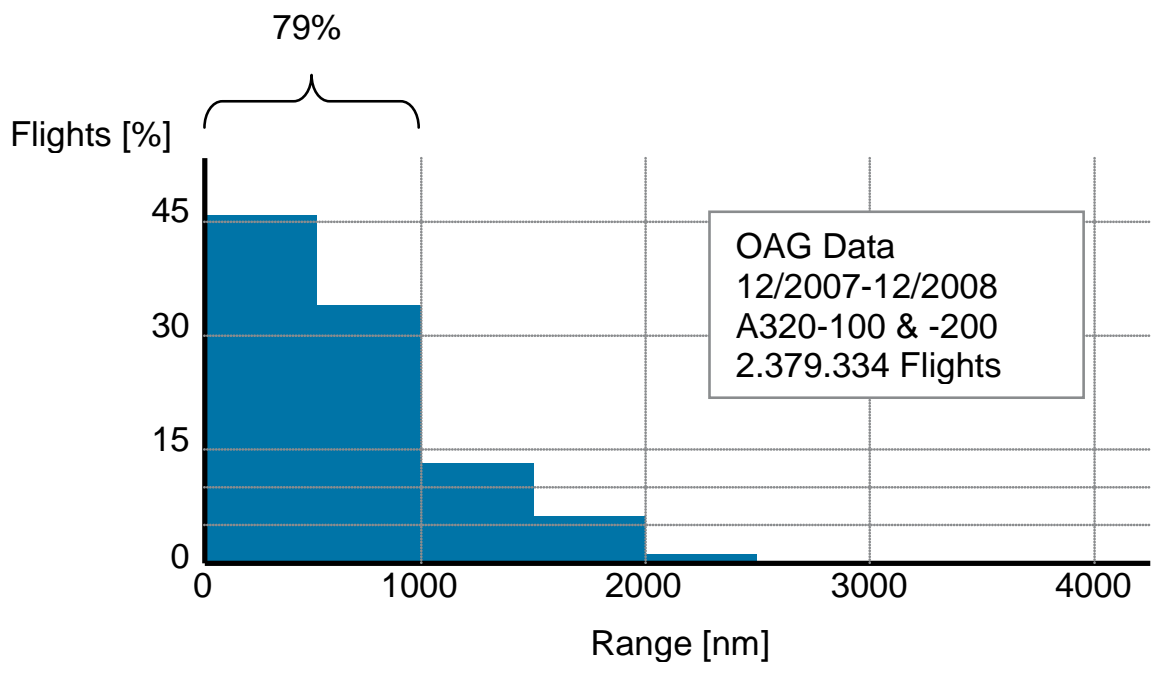

Figure IV-4: Range distribution of short range aircraft

The connective medium size airport substructure is designed to asure time efficient passenger transport with high frequency capacity efficient aircraft movements. Typically spoke airports of about 10-25 MPax/year are addressed, $95 \%$ of these airports offer a take off field length of at least $2500 \mathrm{ft}$, which is selected as the requirement for the short take off and landing capability for the short haul aircraft, see figure IV-5. 


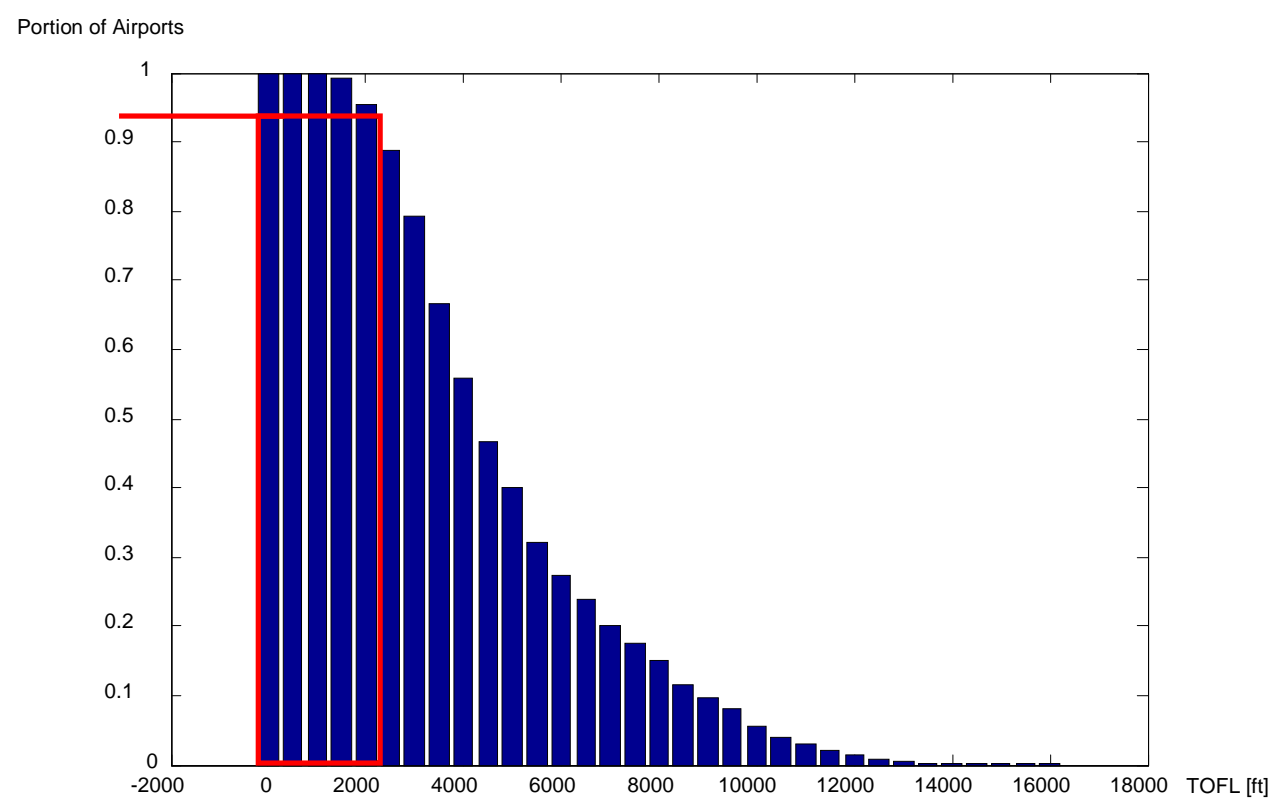

Figure IV-5: Take Off field length distribution of Airports

Here, the airport concept shall provide extended capacities according to Vision 2020 by realizing higher frequencies and slots of flights on depending runways. Further new APRON designs should be investigated for this class of airports to speed up the turn around process. Inside the terminal new processes and technologies for check-in and security check as well as for boarding are to be developed. Especially the later is one paramount interface also for future aircraft designs.

The concept for the air transportation infrastructure and processes (ATIP) ATM-substructure is defined close to the SESAR-ATM-Masterplan, which covers most of the CNS and ATM technologies envisaged up to 2030+, see ref.[10]. Table IV-1 provides an overview of the relevant key performance areas (KPA) and indicators (KPI). Although the SESAR master plan is only targeting at the 2020 timeframe, it is considered to be relevant for 2030+ as well. This is due to the comprehensive efforts that are required to change and improve this substructure. The ATIP model will include procedures like CDA as well as new regional airspace structures and airspace management processes which support higher capacities in the vicinity of airports. New en route procedures e.g. for shorter distance flights at lower altitudes will be considered also. Also those concepts from ATIP directly influence the aircraft design.

A further relevant substructure or stakeholder in terms of aircraft operations like fleet- and netplanning are the airlines which are characterized by different business models. For both point-to-point airlines as well as for classical network carriers operating a typical hub-spoke-net the operated ranges and the used aircraft types are the predominant factors, ref. [18]. Interestingly from airline perspective there seems to be a tendency to bigger aircraft as mentioned in ref. [18], which requires more detailed research on that topic.

Since both, point-to-point as well as hub-and-spoke airlines are operating short range aircrafts with different operational concepts, the resulting flight frequencies and ranges are mainly affecting the airport capacities as well as ATM performances. Regarding the airlines itself the different business models are chosen as distinguishing characteristics. 


\begin{tabular}{|c|c|c|c|c|c|}
\hline \multirow[t]{2}{*}{$\longdiv { \mathrm { KPA } }$} & \multirow[t]{2}{*}{ Key Performance Indicator (KPI) } & \multicolumn{2}{|c|}{ Baseline } & \multicolumn{2}{|c|}{2020 Target } \\
\hline & & Year & Value & Absolute & Relative \\
\hline \multirow[t]{8}{*}{ Capacity } & Annual IFR flights in Europe & 2005 & $9,2 \mathrm{M}$ & $16 \mathrm{M}$ & $73 \%$ \\
\hline & \begin{tabular}{|l|} 
Daily IFR flights in Europe \\
\end{tabular} & 2005 & 29,000 & 50,000 & $73 \%$ \\
\hline & $\begin{array}{l}\text { Best In Class (BIC) declared airport capacity in VMC (1 } \\
\text { RWY), mov/hr }\end{array}$ & 2008 & 50 & 60 & $20 \%$ \\
\hline & $\begin{array}{l}\text { BIC declared airport capacity in VMC (2 parallel dependent } \\
\text { RWYs), mov/hr }\end{array}$ & 2008 & 90 & 90 & $0 \%$ \\
\hline & $\begin{array}{l}\text { BIC declared airport capacity in VMC (2 parallel independent } \\
\text { RWYs), mov/hr }\end{array}$ & 2008 & 90 & 120 & $25 \%$ \\
\hline & BIC declared airport capacity in IMC (1 RWY), mov/hr & 2008 & 25 & 48 & $90 \%$ \\
\hline & $\begin{array}{l}\text { BIC declared airport capacity in IMC (2 parallel dependent } \\
\text { RWYs), mov/hr }\end{array}$ & 2008 & 45 & 72 & $60 \%$ \\
\hline & $\begin{array}{l}\text { BIC declared airport capacity in IMC (2 parallel independent } \\
\text { RWYs), mov/hr }\end{array}$ & 2008 & 45 & 96 & $110 \%$ \\
\hline $\begin{array}{l}\text { Cost } \\
\text { Effectiveness }\end{array}$ & $\begin{array}{l}\text { Total annual en-route and terminal ANS cost in Europe, } \\
€ / \text { flight }\end{array}$ & 2004 & 800 & 400 & $-50 \%$ \\
\hline \multirow[t]{6}{*}{ Efficiency } & Scheduled flights departing on time (as planned) & & & $>98 \%$ & \\
\hline & Avg delay of the remaining scheduled flights & & & $<10 \min$ & \\
\hline & Flights with block-to-block time as planned & & & $>95 \%$ & \\
\hline & Avg. block-to-block time extension of the remaining flights & & & $<10 \min$ & \\
\hline & Flights with fuel consumption as planned & & & $>95 \%$ & \\
\hline & Avg. additional fuel consumption of the remaining flights & & & $<5 \%$ & \\
\hline \multirow[t]{5}{*}{ Flexibility } & Accommodation of VFR-IFR change requests & & & $>98 \%$ & \\
\hline & Unscheduled flights departing on time (as requested) & & & $>98 \%$ & \\
\hline & Avg delay of the remaining unscheduled flights & & & $<5 \min$ & \\
\hline & $\begin{array}{l}\text { Scheduled flights with departure time as requested (after } \\
\text { change request) }\end{array}$ & & & $>98 \%$ & \\
\hline & Avg delay of the remaining scheduled flights & & & $<5 \min$ & \\
\hline \multirow[t]{7}{*}{ Predictability } & $\begin{array}{l}\text { Coefficient of variation for actual block-to-block times: for } \\
\text { repeatedly flown routes }\end{array}$ & & & $<1,5 \%$ & \\
\hline & Flights arriving on time (as planned) & & & $>95 \%$ & \\
\hline & Avg arrival delay of the remaining flights & & & $<10$ min & \\
\hline & Total reactionary delay & 2010 & & & $-0,5$ \\
\hline & Reactionary flight cancellation rate & 2010 & & & $-0,5$ \\
\hline & Total service disruption delay & 2010 & & & $-0,5$ \\
\hline & Percentage of diversions caused by service disruption & 2010 & & & $-0,5$ \\
\hline \multirow[t]{2}{*}{ Safety } & $\begin{array}{l}\text { Annual European-wide absolute number of ATM induced } \\
\text { accidents and serious or risk bearing incidents }\end{array}$ & 2005 & & No increase & \\
\hline & Safety level (per flight) & 2005 & & & $\times 3$ \\
\hline \multirow[t]{4}{*}{ Environmental } & Avg. fuel savings per flight as a result of ATM improvements & 2005 & & & 0,1 \\
\hline & $\begin{array}{l}\text { Avg. CO2 emission per flight as a result of ATM } \\
\text { improvements }\end{array}$ & 2005 & & & $-0,1$ \\
\hline & Compliance with local environmental rules & & & 1 & \\
\hline & $\begin{array}{l}\text { Number of proposed environmentally related ATM constraints } \\
\text { subjected to a transparent assessment with an environment } \\
\text { and socio-economic scope }\end{array}$ & & & 1 & \\
\hline
\end{tabular}

\section{Table IV-1: ATIP Requirements derived from SESAR Masterplan}

This brief description of the short haul transport concept shows that future system level based concept developments must consider all main substructures. The goal is to achieve a balanced design by managing the interdependencies and interfaces. Furthermore, the definition of such new concepts will be based on capabilities rather than on physical requirements. Since substructure performances rely on the capabilities of other systems, describing the interfaces between the substructures will play a very important role. Based on the capabilities and interfaces, technical requirements and eventually concrete physical solutions and processes will be developed.

Figure IV-6 finally gives an overview about the general VIP1 concept definition. 


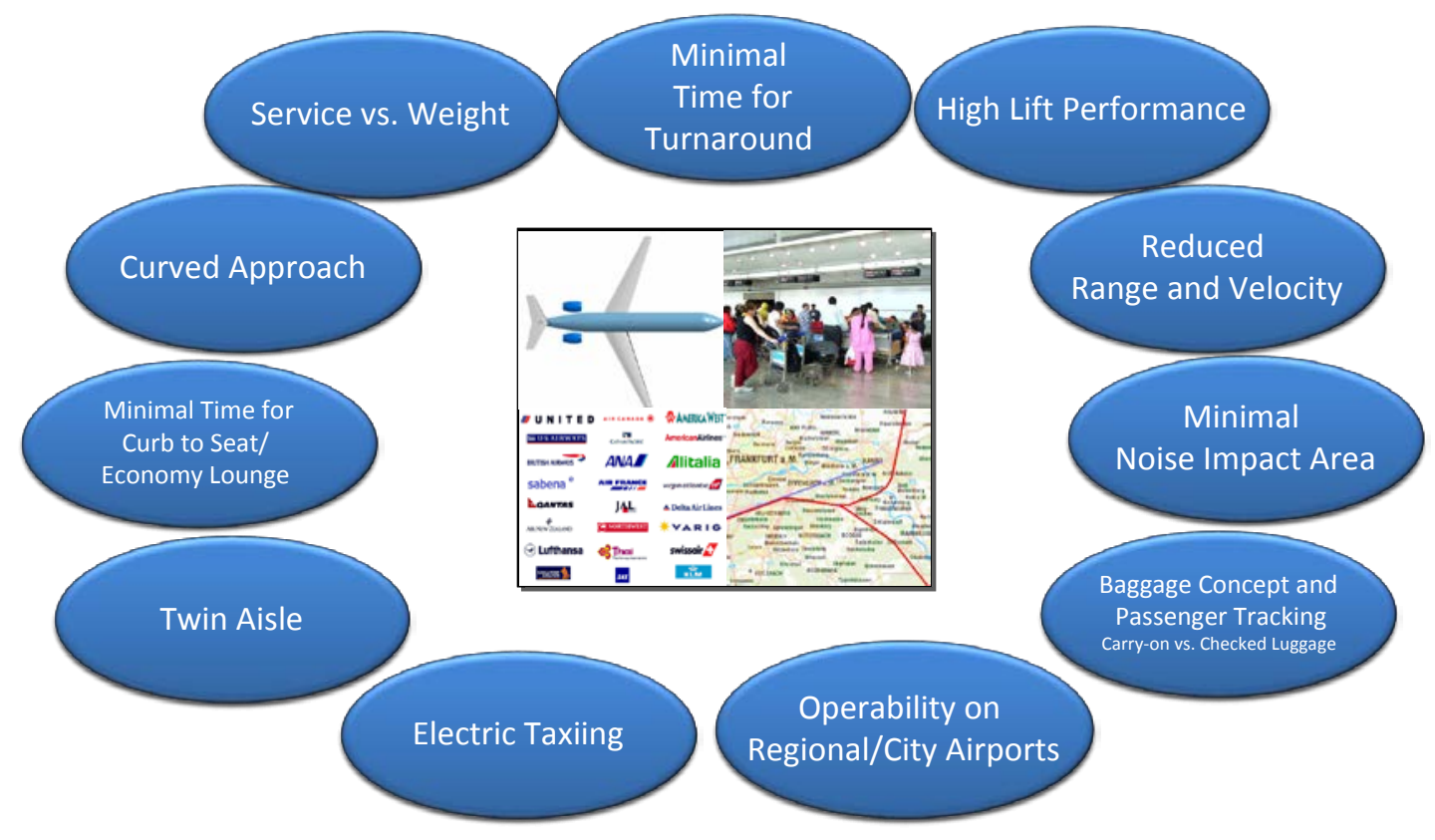

Figure IV-6: VIP1 Short Range Air Transportation Concept “Silent and Clean”

Selecting suitable alternatives plays a critical role in this phase. This approach will also drive the "hard" performance figures like cruise speed or altitude as well as airport and airspace capacity.

To develop an air transportation concept in such a way seems to be logical but not obvious when we take rational decision making methods only, like multi criteria decision making (MCDM). Psychologists have shown, that those quantitative and rational methods tend to fail more and more, when revolutionary and fare ahead solutions are to be developed. In this situations intuition and subconscious based on experience and knowledge plays an important role for decisions on complex systems architectures and definitions. To capture intuition and unconscious-based experience methods like the House of Quality (HoQ) are used, so that people start to talk to each other in a common language. The physical implementation (often some matrix-based structure) should be a by-product that captures the aspects discussed by the people that use these methods. What makes people uncomfortable with using these methods is that many engineers are not used to work with matrix-based methods in a team and often consider them "unscientific" or "business-oriented". Many matrix-based methods are in deed well suited when people from different backgrounds need to work together (like in integrated project teams (IPT)s. A basic draw back of rational methods is that they appear to be a bottom-up, pure analytical approach. However, this is usually the way how many of these methods should be used. Methods like the HoQ are transforming domains and therefore tend to be top-down.

Because of the high complexity of air transportation the description above is also characterized by its incompletness which is not of disadvantage. Only distinctive attributes are mentioned, which is also a tribute to engieneering design, where psychologists state, that intuition is mainly based on a few predominant elements and the related environment. As shown by this example engineering methods for complex systems should also consider those nontechnical and psychological aspects to understand how new concepts arise, ref. [14, 13].

\section{Long haul and Individual Transportation Concepts}

In the following section the long haul air transportation concept and the individual transportation concept are briefly introduced following the same definition philosophy as shown for the future short range air transportation. 
“Comfortable and Clean" is representative for long haul transport because for longer flight time cabin comfort and enroute low emission impact play a more important role than for short range flights.

Future scenarios for long range air transport might drive mass transport to provide a high transportation capacity and environmental compatibility mainly. On the other hand high economical performance is required by the airlines. In terms of quality and affordability, cabin comfort and a highly efficient airport-aircraft and airport-airport interfaces need to be considered.

To improve the performance of future aircraft, new engine technologies, an increased aerodynamic efficiency as well as new unconventional configurations need to be considered. The capability to design such configurations comprehensively in adequate accuracy on conceptual level is a further logical decision issue for the definition of this VIP.

In the Middle East mega hubs with about six runways start to emerge. Therefore, such an airport concept should be investigated to find out whether it is really feasible and provides the desired improvements published as the ACARE goals of punctuality and time efficiency. Also the effect of mega hubs on global traffic flows is of interest.

Complying with these trends based on technical knowledge, scientific excitation and plausibility one concept of the VIP concept for long range transport in the time horizon 2030+ could be composed of

- A blended wing body aircraft configuration technology including comfortable mega cabin and cargo loading technologies

- A mega airport hub concept of full passenger service capability

- An airline network operational concept, which covers also intermediate stop operations as a radical new approach allows operational benchmarking between such new BWB and reduced range longe range conventional aircraft

- A single pilot operations ATM technology concept which affects functional and operational capabilities of the aircraft as well as of the ATM system.

These concept target especially functional interfaces and interdependencies of the main ATS stakeholders of the long range mission.
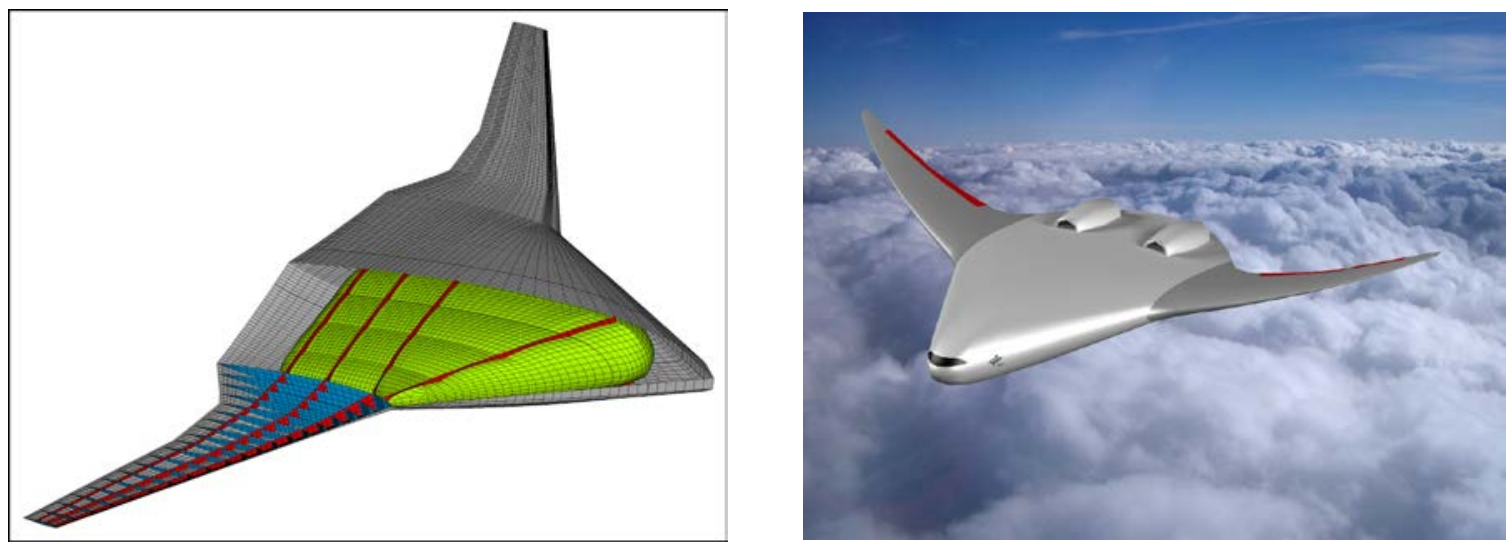

Figure IV-7: Blended Wing Body Concept for Long Haul Air Transportation, ref. [16]

Also briefly mentioned trends of ecological mass transport, efficient big airports and ecological mass transport aircraft as well as high automation reflect most of the ACARE goals regarding environment as well as quality and affordability. 
The overall target of this concept is to investigate how technologies of these four substructures may commonly fulfil ACARE goals of 90\% NOx reduction compared to 2000 (i.e. 80\% until 2020, and further 50\% between 2020 and 2050, qualitiy and affordability and capacity in a balanced way. To achieve these common goals, cooperative research of various disciplines is required. This cooperation must establish a common understanding of the impacts of technologies. Here, the Blended Wing Body configuration has been chosen because it offers the potential for a more efficient passenger mass transport including a highly comfortable cabin in a new primary structure. Comfortable cabins for long range flights are an upcoming request for future mobility due to the long travelling time. The passenger expectation is not only to provide advanced air conditioning and in-flight entertainment but also to develop low energy cabin systems and wider seat pitch. Additionally, establishing the capability to design such a relatively novel concept is itself a research challenge.

All these challenges provide interesting approaches for interdisciplinary research. For example, the aerodynamic potential of drag reduction technologies as well as ideas for weight reduction represent promising research areas. Applying an efficient form of laminar flow control to thick bodies like the BWB is a multidisciplinary problem.

The efficient operation of an aircraft that takes into account the ACARE goals on punctuality and quality leads to the definition of a time efficient mega hub airport. The challenge in this context is to ensure a low turn around time as well as fast, non-disturbing airfield operations. Single Pilot Operation capability is a concept that could be possible in a fully automated ATM system. This technology is not only addressing new system techniques for sensor data fusion but also new procedures concerning take-off and landing as well as emergency procedures and certification issues.

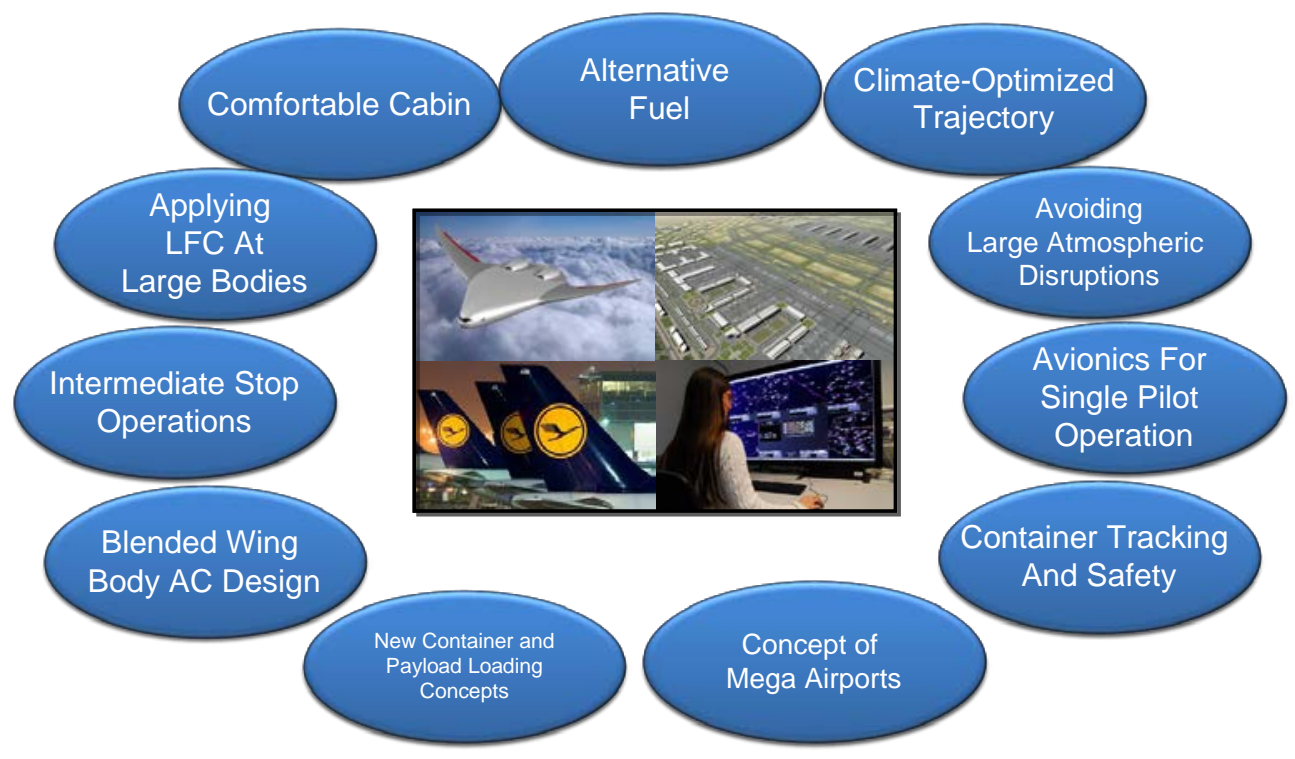

Figure IV-8: VIP2 Long Haul Air Transportation Concept “Comfortable and Clean”

Finally, individual transport highlighted as "Fast and Flexible" reflects the individual request for comfortable and fast transport. This VIP is dedicated to business aviation as another market segement. Supersonic flight is of special interest for this segment. Establishing the concept of operations for supersonic flight includes the question whether there is a need to fly supersonic over land (which is currently forbidden for civil operations in most countries). Furthermore, attractive business models are required for economic operations of supersonic aircraft. Setting up a suitable design capability for supersonic aircraft is one goal of this VIP. The relevant customers in business air transportation request a high level of flexibility and time efficiency. A market analysis has shown, that there are 
realistic business cases for supersonic aircraft in the business aviation sector. These appear more promising than business cases for a aircraft that are similar to the Concorde, ref. [11].

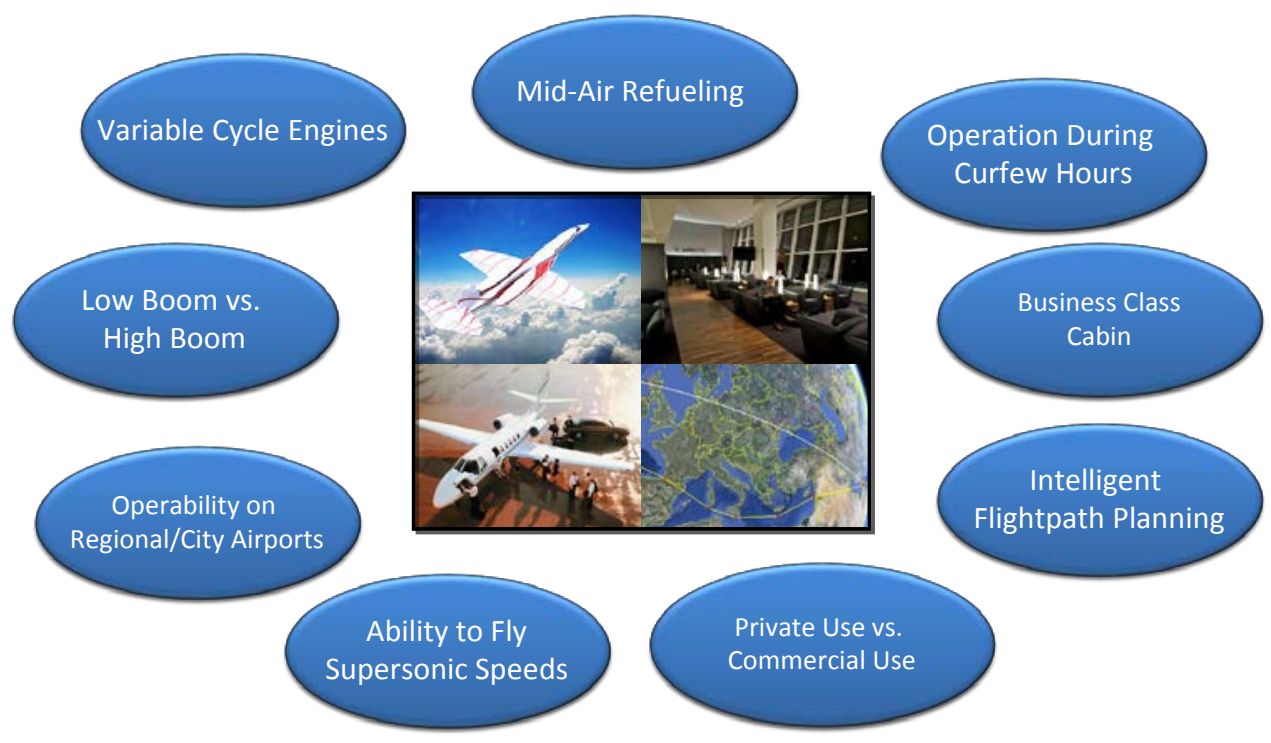

Figure IV-9: VIP3 Individual Air Transportation Concept "Flexible and Fast”

Although from an ecologial perspective, supersonic flight is seen as a challenging issue research on prospective concepts and technologies need to be developed that provide an environmental compatible transportation concept for supersonic flight. This will include appropriate business models for aircraft operators as well as adequate spatial route planning and airport selection. To gain additional operational performance, advanced concepts like mid-air refuelling may fit to this market segement.

\section{Design Environment}

The development of future integrated air transportation concepts that facilitate potential improvements by system integration and balanced interfaces requires the set up of adequate modelling and design environements.

In a collaborative activity, the German Aerospace Center has developed a design environment called VAMP (Virtual Aircraft Multidisciplinary Analysis and Design Processes), ref.[12].

The core element of this environemnt is a common XML-based description language called CPACS (Common Parametric Aircraft Configuration Standard). Originally intended to parameterize aircraft, the language is now developed to also include other air transportation substructures like airports, ATIP and airlines.

The aircraft sizing and analysis code VAMP starts with reduced-order handbook methods (top box in figure IV-10) based on existing aircraft data. Then, more detailed disciplinary physical design tools (e.g. "lifting line" box in the center of figure IV-10) are triggered in a tool chain and different design loops are executed.

Currently CPACS is introduced at TU Delft, KTH Stockholm, Stanford University and Virginia Tech University to interface other aircraft design tools to the DLR tool chain. This modular approach allows aircraft designers to use their tools in conjunction with other tools and set up an appropriate individual design environment that can work on different levels of detail. 


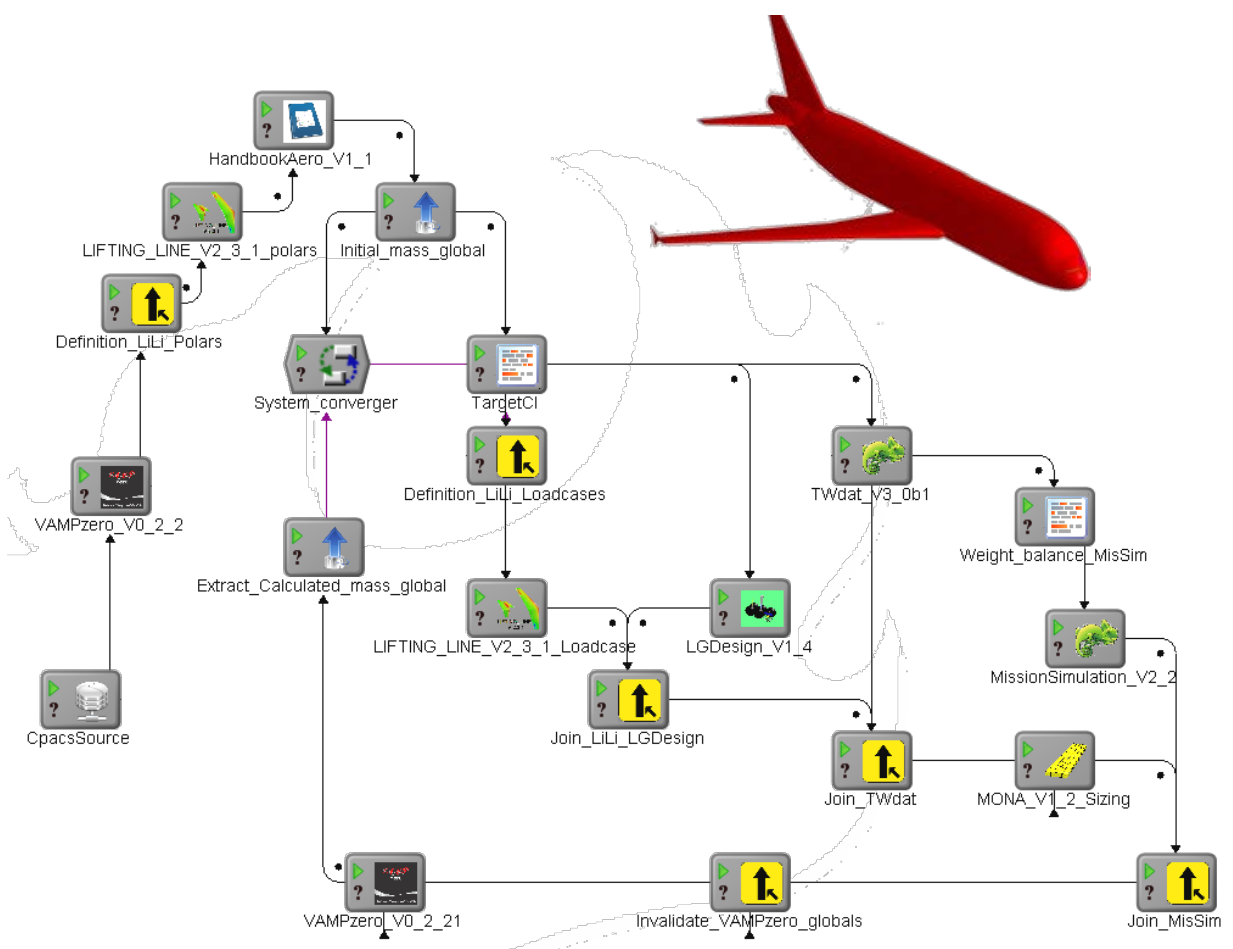

Figure IV-10: Virtual Aircraft Multidisciplinary Design and Processes Tool Chain

The currently running DLR VAMP project uses CPACS for integrated aircraft design. At the end of the project there will be a de-centralized and integrated aircraft design environment available which is used for the VIP1 QSTOL and VIP2 BWB aircraft design.

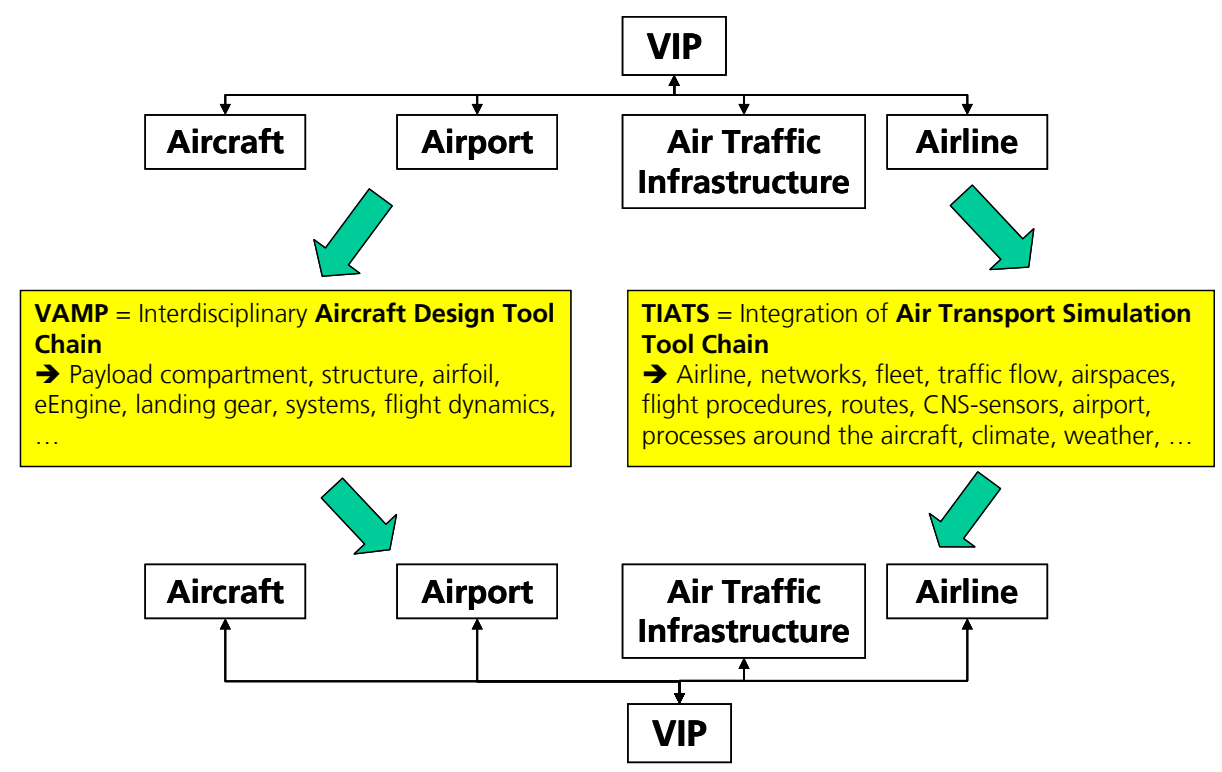

Figure IV-11: VIP -ATS-Substructures and Tool Chain Integration 
A similar tool architecture called TIATS (Total Integrated Air Transportation System) will be setup and interfaced to the VAMP environment to represent new airport and ATM technologies, but also new airline operational concepts.

Both tool chains are used to develop and integrate new technologies and concepts for entire future air transportation systems.

\section{E. Example for a single technology analysis and assessment}

As a first usecase for the setup and proof of the general VIP-methodology, some preliminary analysis for the impact of new technology on a fleet network were performed. Therefore, a short range aircraft that employs natural laminar flow technologies on a forward swept wing was infused in an existing fleet.[16]. The airline network was then optimized for maximal profit.
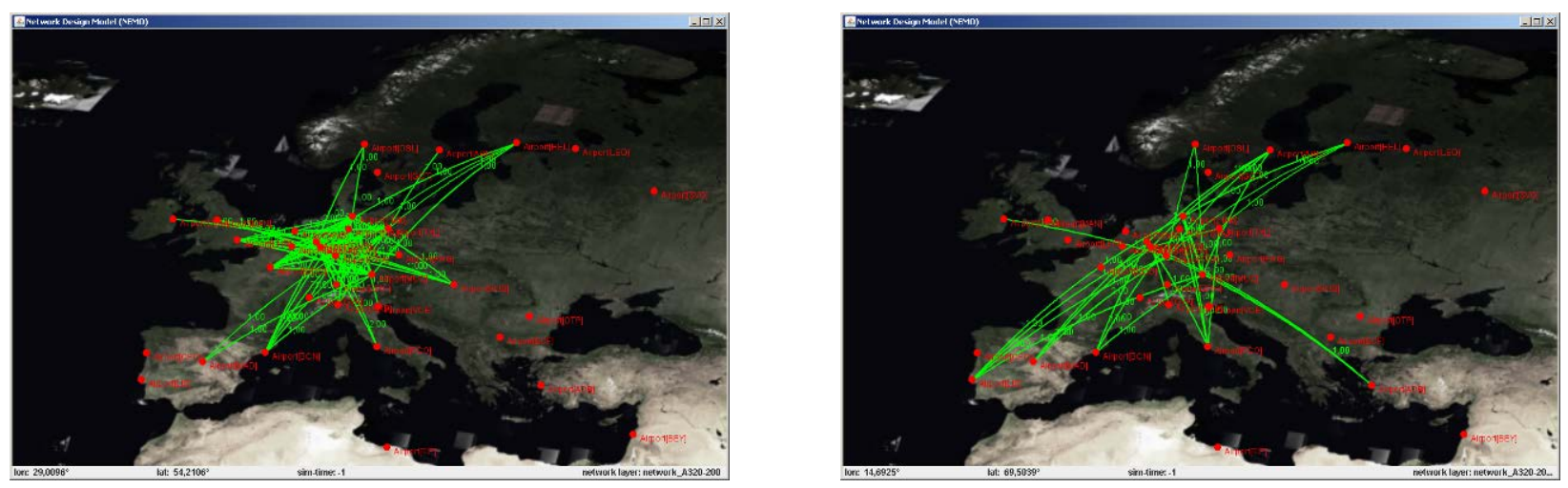

Figure IV-12: Variation of airline network due to laminar flow aircraft fleet introduction for max. profit

Figure IV-12 shows that on a fleet level, the optimal network for aircraft that use natural laminar flow technology incorporates relatively long routes (right picture) The optimal network for a fleet of conventional aircraft incorporates shorter routes (left figure). Although the airline can serve its destinations, frequency and density of flights is reduced, when maximum profitability is required. More detailed analysis is ongoing to verify this initial oberservations.

In a second step the blockfuel consumption in the network were analysed. The results show that on ranges below $750 \mathrm{~km}$, using aircraft with natural laminar flow may actually increase the block fuel consumption. This is because the conceptual design of the aircraft the uses natural laminar flow has a higher MTOW compared to the reference aircraft. On short ranges, the MTOW penalty increases the fuel consumption of the NLF aircraft. For greater ranges, the drag reduction during the cruise segment leads to a reduced amount of consumed fuel.

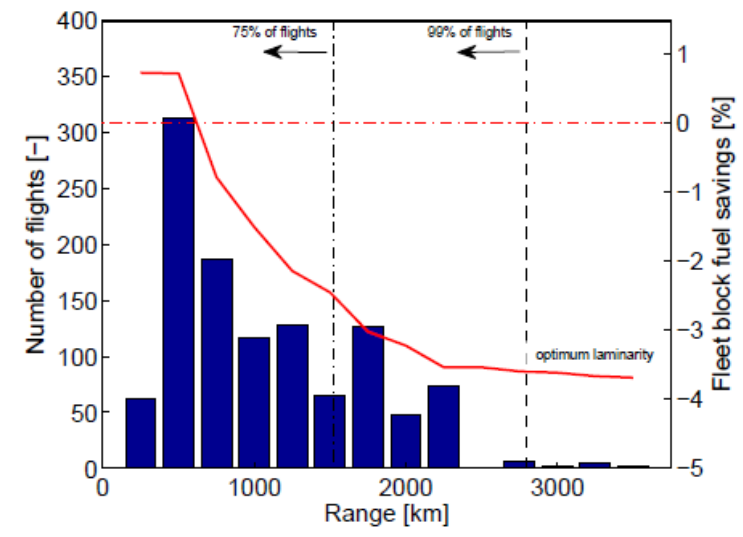

Figure IV-13: Block Fuel Savings and Number of Flight depending on Range

American Institute of Aeronautics and Astronautics 
Figure IV-13 indicates that for an airline network that provides the most profit, most of the flights are performed at or below approximately $750 \mathrm{~km}$. There, natural laminar flow can not show its benefits. Although the optimised net is profitable, the profit is mostly generated by the longer flights.

This final example gives a first impression, how considering substructures on a higher system level can help in optimizing some of the ATS substructures in a balanced way. In this small example aircraft design issues and airline operational aspects were merged. The next steps will also include investigations of airport and ATIP concerns.

\section{Conclusion}

To enable a balanced optimization of substructure technologies, concepts to improve the efficiency of the air transportation system need to be developed in an interdisciplinary and integrated environment.

For this purpose, the DLR Institute for Air Transportation Systems has developed the concept of Virtual Integration Platforms (VIP) as, an integrated development environment for future ATS concept integration. Based on a scientific and design engineering approach 2010 technology reference ATS are developed to demonstrate the benefit of new technologies of future concepts compared to todays capabilities.

Future concepts targeting the EIS horizons of 2030+ and later are composed of expected trends and technologies which will be developed for different substructures to demonstrate their potentials as individual technologies but especially also to assess their benefits and potentials in an integrated environment. The definition of those future concepts especially concerning the selected technologies are used for technology development and assessment for the next years. The development of the VIP concept has shown, that pure scientific engineering methods like rational system engineering methods and multi criteria decision making are not sufficient to define and develop new concepts for the future. The ability to overcome pure logical approaches and to understand gut feeling knowledge of scientists is a major prerequisite to explore new concepts. This will become an objective for future research on interdisciplinary engineering processes and the handling of complex systems. The early definition process has shown that the system interfaces have a significant influence on the definition and selection of appropriate technologies. Choosing a suitable technology integration strategy it is necessary to create complex systems and to provide the environment for detailed physical research. This paper described the initial efforts on defining Virtual Integration Platforms.Drawing on these initial experiences, the design and development of the various substructures for the virtual integration platform "quiet and clean" will be the next step.

\section{References}

${ }^{1}$ N.N: EUROPEAN AERONAUTICS: A VISION FOR 2020, REPORT OF THE GROUP OF PERSONALITIES JANUARY 2001, Luxembourg: Office for Official Publications of the European Communities, 2001

${ }^{2}$ N.N: Strategic Research Agenda, Volume 1, Advisory Council For Aeronautics Research in Europe, October 2002, www.acare4europe.org

${ }^{3}$ N.N: Strategic Research Agenda, Volume 2, Advisory Council For Aeronautics Research in Europe, October 2002, www.acare4europe.org

${ }^{4}$ F. Quentin, J. Szodruch: 2008 Addendum to the Strategic Research Agenda Advisory Council for Aeronautics Research in Europe, 2008, www.acare4europe.org

${ }^{5}$ E.M. Greitzer, et. Al.: N+3 aircraft Concept Designs and Trade Studies, Final Report, Volume 1, NASA/CR-2010216794/Vol.1, NASA, December 2010

${ }^{6}$ N.N.: Flightpath 2050 - Europe's Vision for Aviation, Report of the High Level Group on Aviation Research, ISBN 978-92-79-19724-6, Publications Office of the European Union, 2011

${ }^{7}$ S. Langhans, E. Stumpf, V. Gollnick,: „A Holistic Approach to evaluate the Air Transportation System”, ICAS Conference, Paper 228, Anchorage 18-23 September, USA, 2008

${ }^{8}$ S. Langhans: "A Systems-Engineering based Methodology for Economic ATS Concepts Assessment, Ph.-D. Thesis, Institute for Air Transportation Systems, Technical University Hamburg-Harburg, to be published 
${ }^{9}$ T. Schilling: „A Systems Engineering Approach for Air Transportation System Definition”, Institute for Air Transportation Systems, IB LK-SA-004/09, Hamburg, 2009 - in German

${ }^{10}$ N.N.: ”ATM Master Plan Update Working Group Report, edition 1.1, SESAR Joint Undertaking, European Commission, http://atmmasterplan/faces/public/ur/change_history.jspx March 27 ${ }^{\text {th }}, 2010$

${ }^{11}$ B. Liebhardt: "Economical, technical and regulatory conditions for a Supersonic Business Transportation concepts and resulting requirements”, DLR Air Transportation Systems, IB 328-XXX-2010, Hamburg, Germany, 2010, in German

${ }^{12}$ D. Boehnke, B. Nagel, V. Gollnick: „An Approach to Multi-Fidelity in Conceptual Aircraft Design in Distributed Design Environments”, IEEE Aerospace Conference, 2011

${ }^{13}$ M. D. Griffin: "System Engineering and the Two Cultures of Engineering”, Boeing Lecture, Purdue University, 2007, http://www.spaceref.com/news/viewsr.html?pid=23775, last access August $18^{\text {th }}, 2011$

${ }^{14}$ G. La Rocca, M. van Tooren: "Knowledge Based Engineering to support aircraft multidisciplinary design and optimization”, Journal of Aerospace Engineering 224 (2010), 1041-1055

${ }^{15}$ G. Gigerenzer: „Gut Feelings“, Viking Publishing, New York 2007, ISBN 978-0-670-03863-3

${ }^{16}$ P.D. Ciampa, B. Nagel, M. van Tooren: “Global local structural optimization of transportation aircraft wing”; 51st AIAA Structures, Structural Dynamics, and Materials Conference, 12 - 15 Apr 2010, Orlando, Florida.

${ }^{17}$ M. Braun, K. Wicke, A. Koch, T. Wunderlich: „Airline Systems Analysis of Natural Laminar Flow based on Network Design and Integrated Fleet Planning”, paper submitted to $11^{\text {th }}$ ATIO conference Virginia Beach 2011

${ }^{18}$ N.N: “Big Future ahead?!, Flight international $17^{\text {th }}-23^{\text {rd }}$ of May 2011

${ }^{19}$ X. Sun, Y. Li, “An Intelligent Multi-Criteria Decision Support System for Systems Design”, 13th MAO \& 10th Aviation Technology Integration and Operation Conference, 2010.9.13-15, Texas, USA

${ }^{20}$ X. Sun, Y. Li: "Evaluation of Control System Performance Using Multiple Criteria Decision Making Techniques”, 49th IEEE Conference on Decision and Control, 2010.12.15-17, Atlanta, USA

${ }^{21}$ X. Sun, V. Gollnick, E. Stumpf: "Extension of Robust Control \& its Combination with MCDM", 20th International Conference on MCDM, Chengdu, China, 2009.6.21-26

${ }^{22}$ K. Wicke, M. Kruse: “Mission and Economic Analysis of Aircraft with Natural Laminar Flow Technology”, 11th Aviation Technology Integration and Operation Conference, 2011.9.20-23,Virginia Beach, USA 